\title{
A RELAÇÃO ENTRE MANUSCRITOS E IMPRESSOS EM TUPI COMO FORMA DE ESTUDO DA POLÍTICA LINGÜÍSTICA JESUÍTICA NO SÉCULO XVIIINA AMAZÔNIA
}

Maria Cândida Drumond Mendes Barros*

\section{Introdução}

\begin{abstract}
$\mathrm{O}$ objetivo será analisar um conjunto de catecismos, gramáticas e dicionários manuscritos em tupi do século XVIII como espaço de ação da política jesuítica de estandardização nesta língua. Estamos definindo esta política como o processo de fixação, no interior da Companhia de Jesus, de um repertório valorizado de formas, léxicos e enunciados em tupi identificados pelas obras impressas, tais como as gramáticas de Joseph Anchieta (1990) e de Luis Figueira $(1621 ; 1687)$ e os catecismos de Antônio de Araújo $(1618 ; 1686)$ e Filipe Bettendorff (1687). Esta situação de estandardização do tupi no século XVIII na Amazônia pode ser encontrada no relato do jesuíta João Daniel. Ele diferencia duas variedades de tupi, uma identificada como
\end{abstract}

* Museu Emílio Goeldi (Belém/Pará). 
"língua geral verdadeira", presente nas obras impressas em tupi, e a outra, a "língua geral corrupta", em uso oral no cotidiano das missões. Segundo Daniel, a variedade de tupi usada no cotidiano das missões não se identificava mais com aquela fixada no material impresso. O catecismo já não era mais compreendido pelos índios (Daniel, 1976, v. 2, p. 227), mas ainda era o texto oficial da prática diária da doutrina.

De que maneira os manuscritos em tupi - passíveis, pela ação do seu escriba, de alterações em relação ao modelo impresso - se posicionaram quanto à diferenciação entre o tupi impresso e o tupi oral na Amazônia no século XVIII? Observaremos se eles conservaram regras e expressões do tupi impresso, seguindo a política de estandardização, ou adaptaram os textos à variedade tupi corrente nas missões, adotando uma política de regionalização.

A análise dos manuscritos setecentistas tupi reunirá recursos da sociolingüística e da historiografia lingüística. Esta última nos levará a levantar dados sobre a circulação das obras impressas em tupi pelas missões e a procurar sinais de consulta destas obras pelos autores dos manuscritos. A sociolingüística participa da análise por meio do conceito de diglossia. Segundo Fasold (1987, p. 53), diglossia é o processo social de diferenciação do repertório lingüístico de uma comunidade entre segmentos altamente valorizados para situações formais e outros considerados menos valorizados, para uso em situações informais. Analisaremos os manuscritos setecentistas sobre o tupi como instrumentos de diferenciação do repertório tupi entre as variedades "verdadeira" e "corrupta".

Mattoso Câmara foi o primeiro autor a definir a política lingüística jesuítica sob o ângulo de um processo prescritivo sobre a língua tupi, que ele nomeou como disciplinarização gramatical. Câmara realça o papel das gramáticas, tais como a de Anchieta e de Figueira, como gênero textual responsável pelo estabelecimento de uma disciplina gramatical. No presente trabalho, consideraremos o catecismo como o principal gênero literário da política jesuítica de estandardização do tupi, devido ao papel deste tipo de obra no interior da Companhia de Jesus, tanto na Europa como nas colônias. As regras da Companhia de Jesus em relação ao catecismo acabaram por nortear a política lingüística dos jesuítas nas missões.

$\mathrm{O}$ trabalho seguirá o seguinte roteiro:

a) levantamento dos catecismos, gramáticas e dicionários tupi manuscritos do século XVIII e apresentação dos problemas para identificá-los temporal e geograficamente; 
b) revisão da tese de Mattoso Câmara sobre a disciplinarização do tupi pelos jesuítas como ponto de partida para a análise empírica;

c) análise do catecismo de Antônio de Araújo $(1618 ; 1686)$ como instrumento jesuítico de estandardização do tupi através da sua difusão como texto padrão da evangelização nas missões na costa do Brasil e na Amazônia desde o século XVII até o XVIII. Não apenas o texto cristão em tupi era o mesmo em todas as missões jesuíticas, como também o cerimonial que o acompanhava;

d) descrição da formação da variedade de tupi "corrupto" como resultado das mudanças na composição etnolingüística das missões no Baixo Amazonas no século XVIII;

e) análise de alguns aspectos da política de estandardização presentes nos manuscritos setecentistas. Observaremos as consultas às obras impressas em tupi e o papel de diferenciação diglóssica que estes documentos estabeleceram, ao determinarem regras e léxicos próprios a cada uma das variedades.

\section{O corpus de manuscritos sobre o tupi de missões na Amazônia do século XVIII}

Os manuscritos setecentistas sobre o tupi contabilizam sete dicionários (seis deles português-tupi), cinco estudos gramaticais, de diferentes extensões, e nove conjuntos de textos religiosos diversos (orações, listas de preceitos, canções, diálogos, confessionários etc.). ${ }^{1}$ Deste conjunto, apenas um -Specimen Linguae Brasilicae Vulgaris, de Anselmo Eckart (Rosa, 1994) - foi impresso no século XVIII, porém sem ser por iniciativa da Companhia de Jesus. A obra foi impressa em 1778 por um editor protestante que apoiou os jesuítas alemães expulsos pelo Marques de Pombal. ${ }^{2}$

1 Ver quadro anexo.

2 Agradeço a Fernando Aymoré as informações sobre Eckart e a cópia do documento de 1778 . 
Uma dificuldade encontrada em relação à maioria dos textos foi a identificação deles quanto aos dois critérios requeridos: serem originários da Amazônia e do século XVIII. Apenas um deles tem data (1771) e local (Belém) definidos. Para os demais documentos, nos serviremos de indícios encontrados ao longo das obras que permitam completar as informações referentes ao tempo e ao local de origem.

A presença de nomes de missionários na obra auxilia na datação e na localização. Por exemplo, a menção ao padre Marcos Antonio Arnofini (16871745) em um dos catecismos permite localizá-lo como um texto em circulação na Amazônia e delimitá-lo temporalmente entre 1728, ano da chegada daquele missionário na região, e 1745, ano de sua morte (Ayrosa, 1950).

Dos três gêneros de obras, os dicionários deixam mais pistas para situálos geográfica e temporalmente. O verbete para inverno, traduzido como amaná ara (tempo de chuvas ${ }^{3}$ ), sugere que estas obras são da região amazônica, e não da costa do Brasil, onde o clima no inverno não é caracterizado pelas chuvas e sim pelo frio. O dicionário português-tupi de 1621, de Piratininga (São Paulo) (Ayrosa, 1938), traduz inverno como "roig", a mesma palavra para frio.

Outros verbetes, ao se referirem a locais da região, como Marajó e Mortigura, reforçam que estes materiais procediam da Amazônia. Mortigura está no verbete para "morador" do documento Prosódia ("Morador, ou natural. Igoara ut Mortigurigoara"). O fato de nomear esta missão pelo seu nome prépombalino (Mortigura) permitiria aventar que a obra é anterior à transformação das missões religiosas em vilas, com nomes portugueses, por ordem de Pombal. Este foi o caso de Mortigura, que passou a se chamar Vila do Conde.

\section{A tese de Mattoso Câmara sobre disciplinarização do tupi colonial pelos jesuítas}

Pelo menos em duas obras, Câmara associa o conceito de disciplinarização gramatical ao uso do tupi pelos jesuítas: Dicionário de Filologia e gramática referente à língua portuguesa (1964) e Introdução às línguas indígenas brasileiras (1965). Para Câmara (1964), disciplina gramatical é o "conjunto de prescrições que se estabelecem para impor uma norma lingüística no uso falado

3 Agradeço a Antônio Luis Lessa por ter chamado atenção para sua tradução. 
e escrito". As prescrições discriminariam as formas de palavras, de sentidos e de sentenças consideradas legítimas em uma língua (Câmara, 1964, p. 114). Elas se estabeleceriam por mecanismos sociais, tais como a escola e a ação dos gramáticos, que poderiam favorecer a que determinadas formas lingüísticas sejam privilegiadas em detrimento de outras em alguns domínios sociais. Foi este tipo de interferência de caráter prescritivo que Câmara definiu como tendo sido exercido pelos jesuítas sobre o tupi por meio de textos escritos, tais como as gramáticas de Anchieta e Figueira.

A concepção de Câmara de que as obras escritas sobre o tupi tiveram repercussões normativas nesta língua surgiu mais em virtude de suas posições teóricas do que como fruto de uma pesquisa empírica em relação ao tema colonial. Câmara era partidário da posição do lingüista Josep Vachek - autor que ele inclui na sua bibliografia do Dicionário de Filologia e gramática referente à língua portuguesa - para o qual a escrita não poderia ser considerada apenas como uma representação da fala, mas como desencadeadora de "novas condições de funcionamento da linguagem" (Câmara, 1964, p. 131). A escrita estabeleceria um processo de disciplinarização em uma língua, ao estabelecer uma diferenciação entre formas lingüísticas privilegiadas pela escrita em oposição a outras que fossem excluídas (Câmara, 1965, p. 103).

No livro Introdução às línguas indígenas brasileiras (1965), Câmara desenvolve a idéia de que a disciplinarização do tupi teria representado uma sistematização simplificada desta língua ao fazer uso da gramática latina como modelo. Esta simplificação teria tido repercussões na fala dos índios, resultando no surgimento de um tupi modificado (Câmara, 1965, p. 102). No entanto, a hipótese de Câmara de que as gramáticas jesuíticas tupi foram uma sistematização simplificada desta língua foi rejeitada em análises sobre as obras de Anchieta e de Figueira (Leite, 2000; Rodrigues, 1997), que apontaram para a acuidade destas gramáticas jesuíticas na descrição de traços fonéticos, morfológicos e sintáticos do tupi.

A tese de Câmara a respeito da disciplinarização do tupi pelos jesuítas desvinculada da tese da simplificação gramatical - será o ponto de partida para o estudo sobre o papel prescritivo da escrita tupi, estabelecido por catecismos, gramáticas e dicionários do século XVIII no interior da Companhia de Jesus. A disciplinarização - aqui definida como estandardização - será estudada como um processo social, no qual procuraremos identificar os agentes e os instrumentos que promoveram este processo prescritivo. 


\section{A política jesuítica de estandardização do tupi por meio do catecismo}

\section{O catecismo como gênero textual da evangelização jesuítica}

O catecismo teve seu apogeu no século XVI, no contexto da disputa teológica entre católicos e protestantes. Na Igreja tridentina, este gênero textual se consolidou como um roteiro do que dizer e de como atuar no "ministério da doutrina" (Jorge; Martins, 1602), situação institucionalizada entre padres e fiéis, dirigida à evangelização das crianças e das parcelas pouco letradas da população. Várias instituições surgiram dirigidas a evangelizar crianças. Entre as ordens religiosas criadas com este objetivo, a mais importante foi a Companhia de Jesus. Pelas suas regras, todos os seus membros tinham a obrigação de ensinar a doutrina para crianças pelo menos 40 dias ao ano, sob pena de estarem incorrendo em pecado mortal (FernandesVieira, 1981, p. 44).

A importância do "ministério da doutrina" entre os jesuítas fez com que eles predominassem como autores de catecismos em vários países da Europa no século XVI, principalmente no estilo de obra dirigida a crianças e a adultos com pouca instrução: na Espanha, Jeronimo Ripalda (1591) e Gaspar Astete (1593); na Alemanha, Pedro Canísio (1556); na Itália, Roberto Belarmino (1597). Em Portugal, os jesuítas Marcos Jorge e Inácio Martins foram autores de um catecismo popular, que recebeu várias reedições (a primeira, em 1566).

O catecismo europeu foi levado para as colônias como principal texto de evangelização. Essa transposição pode ser acompanhada pela difusão que teve a obra de Marcos Jorge e Inácio Martins como modelo de "doutrina" nos domínios coloniais de Portugal. As línguas nas quais houve tradução e impressão deste catecismo foram a tamul, em $1579,{ }^{4}$ a japonesa, em $1592,{ }^{5}$ a konkani, em

4 "Doctrina Christãa, a maneira de Diálogo: feyta em Portugal pello Padre Marcos Jorge da Companhia de IESU: tresladada em língua Malauar Tamul, pello padre Anrique Anriquez da mesma Companhia. Impressa cõ approvação do Ordinario, E Inquisidor, E com licençca do superior. Em Cochim, no Collegio da Madre de Deus.” (Boxer, 1956)

5 "Nippon no Iesus no Companhia no Superior yori Christan ni soto no cotouari uo tagaino mondo no gotoqu xidai uo vacachi taamo Doctrina.... Amacusa". (Maruyama, 1998) 
$1622,{ }^{6}$ e a kikongo, em $1624 .^{7}$ No caso do tupi, foi feita uma tradução do catecismo de Marcos Jorge em 1574 pelo jesuíta Leonardo do Vale (1538-1591).

El Pe. Leonardo compuso este año [1574] una doctrina en la lengua del Brasil quase tresladando la que hizo el Pe. Marcos Jorge de buena memória. (História..., 1897, p. 117)

O diálogo de perguntas e respostas foi um traço característico dos catecismos jesuíticos tanto na Europa como nas colônias. Em sua maioria, o mestre pergunta e o discípulo responde. $\mathrm{O}$ catecismo em forma de pergunta de exame não era uma criação jesuítica, porém a Companhia foi responsável pela sua generalização como modelo de catecismo popular tridentino.

A rotina da doutrina em Portugal e nas colônias era a mesma se compararmos as recomendações em relação às forma de usar o catecismo em Inácio Martins, em Portugal, e em Antônio Vieira, na Amazônia. No texto "Lembrança pera quem ensinar a Sancta Doctrina", Inácio Martins (Jorge; Martins, 1602) instrui o prelado quanto à forma de fazer uso do catecismo, descrevendo o cerimonial a ser seguido na doutrina: começava pela oração da Ave-Maria, cantada com todos os participantes em joelhos. Depois saíam em procissão com bandeira de Nossa Senhora, com o padre ou o irmão na frente, tocando uma campainha para chamar as crianças. A procissão deveria ir em direção à igreja ou à praça pública cantando ladainhas. Na chegada à praça, a doutrina tinha início pelas orações ditas com os meninos. Depois, havia uma sessão em que as crianças deviam se arrepender das ações erradas. Na etapa seguinte, dois moços de "boa fala" subiam em um lugar alto para ler trechos do catecismo. Ao final de cada capítulo, o padre deveria relatar algum caso exemplar. Para cada uma dessas partes da doutrina, as crianças que melhor memorizassem o texto ganhavam prêmios (Jorge; Martins, 1602).

6 "Doutrina christam em lingoa bramana canarim: ordenada a maneira de diálogo, pera ensinar os mininos / coposta pollo Padre Thomas Estevao... natural de Lodres. [Rachol]: empressa no Collegio de Rachol da Companhia de Jesus" (MARUYAMA, 1996).

7 "Doutrina christaa./ Composta pelo P. Marcos Jorge.../ Acrescentada pelo Padre Ignacio Martinz.../ De novo traduzida na lingoa do Reyno de Congo,/ por ordem do P. Mattheus Cardoso theologo, da Companhia de Jesus. Lisboa: por Geraldo da Vinha" (MARUYAMA, 1996). 
Pelas cartas dos jesuítas nas colônias se pode constatar que o ritual da doutrina em Portugal foi transposto para as colônias portuguesas. Na segunda metade do século XVII, vamos encontrar o mesmo cerimonial da doutrina de Marcos Jorge presente na rotina dos jesuítas na Amazônia. A procissão antecedendo a doutrina continuou sendo realizada, porém a ordem dos participantes no cortejo correspondia às hierarquias estabelecidas localmente, como a distinção entre principais (na frente) e demais índios (no final).

Saímos da nossa igreja à uma hora. Levamos adiante um grande pendão branco com a imagem do santo Padre Inácio, que leva algum índio principal das aldeias, se o há na cidade, ou se não outro de respeito. Vão os nossos estudantes cantando a ladainha. Damos volta pelas ruas principais, levando os índios adiante e as índias atrás, pedindo aos portugueses que estão pelas portas e janelas que os mandem, e, se é necessário, compelindo os que ficam; e desta maneira, com uma muito comprida procissão chegamos à Matriz, e ali, postos os índios de um lado da igreja e as índias do outro, lhes faz o padre a doutrina, ensinando-lhes primeiro as orações do catecismo, e depois declarando-lhes os mistérios da fé, preguntando e premiando os que melhor respondem. (Vieira, 1970, p. 350)

A circulação do catecismo tupi entre os índios ocorria por meio de uma rede formada por letrados (missionários) e não-letrados (índios). Os missionários eram os intermediários da difusão dos textos escritos em tupi entre os índios. O catecismo tupi era uma obra para ser lida pelo missionário e não pelo indígena.

A forma de aprendizagem dos textos cristãos em tupi pelos índios se dava pela memorização por via da oralidade. $\mathrm{O}$ ensino das orações ocorria pela contínua repetição nas horas de doutrina: "Dão conta das coisas da fé por um formulário de perguntas (...) fazendo um de mestre os outros de discípulos, repetiram por ordem a Doutrina Cristã" (Anchieta, 1556 apud Cardoso, 1992, p. 22). Também para os catequistas, índios encarregados da doutrina na ausência dos padres, o aprendizado da doutrina era feito pela memória. Em relação aos índios novatos na missão, o aprendizado dos diálogos da doutrina devia ocorrer nos primeiros dois anos em que estivessem nas missões. Neste período, eles 
eram poupados do trabalho obrigatório para os colonos com o objetivo de aprenderem os diálogos da doutrina.

O catecismo tupi colonial teve um caráter de texto obrigatório tanto para índios como para os missionários. Os diferentes textos que compõem o catecismo (diálogos, orações, lista de preceitos, fórmulas dos sacramentos etc.) tinham como regra que eles deveriam ser repetidos verbatim. As respostas dos índios às perguntas do missionário já estavam pré-elaboradas. Para os missionários, o catecismo deveria ser usado sem alteração tanto por aqueles que soubessem a língua como por aqueles que a desconheciam.

Para os índios, o conhecimento das orações e dos diálogos de doutrina era uma exigência para ser reconhecido como índio forro. Saber os diálogos de perguntas e respostas era a forma do aprendizado religioso. Estes diálogos tiveram múltiplas funções na vida do índio cristianizado. Antes de um índio se casar, confessar ou ser batizado, o missionário deveria lhe fazer as perguntas do catecismo (Araújo, 1686, p. 191).

\section{Formação do catecismo tupi de Antônio de Araújo na costa do Brasil e sua difusão na Amazônia}

O catecismo, como um roteiro de um diálogo obrigatório entre padre e fiéis, que deveria ser repetido verbatim por ambos, levou a uma política de padronização deste texto ao longo das missões na costa do Brasil e na Amazônia. A fixação deste texto era a condição para que ele pudesse ser usado verbatim em todas as missões, sem prejuízo pelas contínuas mudanças dos jesuítas das missões.

A política jesuítica de padronização do texto cristão em tupi pode ser acompanhada por meio da história da formação do catecismo de Antônio de Araújo (1566-1632) na costa do Brasil e sua difusão nas missões do norte. Este foi o primeiro catecismo tupi impresso sobre a égide dos jesuítas, tendo recebido duas edições, com modificações entre elas. Um terceiro catecismo tupi impresso foi o do jesuíta alemão Felipe Bettendorff, em 1687, porém esta obra ratifica a obra de Araújo, ao manter os mesmos textos das orações e das listas de preceitos.

Em várias partes da obra de Araújo é dito que o texto havia sido "composto a modo de diálogos por Padres Doctos, e bons lingoas da Companhia de Jesus" e que Araújo havia sido responsável pela sua ordenação e alterações. Uma série 
de missionários está associada à elaboração deste catecismo tupi. Serafim Leite (1938, v. 9, p. 439) cita pelo menos sete jesuítas, todos da jurisdição do Estado do Brasil: Azpilcueta Navarro, Pero Correia, Leonardo do Valle, José de Anchieta, Luis da Grã, Antônio de Araújo e Bartolomeu de Leão.

O mecanismo usado pela Companhia de Jesus para manter a homogeneidade do texto cristão em tupi na sua forma manuscrita foi a "publicação", que no dicionário de Bluteau se define como tornar um texto notório a todos pela circulação de uma cópia autenticada. A "publicação" do catecismo tupi manuscrito foi um ato exercido pela hierarquia jesuítica, que definia uma versão tupi como oficial e a difundia pelas missões com a exigência de não modificá-la. A forma de autenticar um catecismo, por exemplo, era a sua inclusão no "Livro das casas", que incluía todas as informações necessárias ao missionário (Leite, 1938, v. 2, p. 557).

A autenticação de uma versão do catecismo tupi como a oficial pode ser encontrada em 1586, quando o visitador Fernão de Cardim aprova um texto, com o preceito de que não se devia modificá-lo ao gosto dos missionários (Leite, 1938, v. 2, p. 306-307).

A impressão como forma de manter o texto do catecismo tupi padronizado foi um mecanismo tardio, se considerarmos que em três ocasiões (Thevet, 1575; Ore, 1607; Evreux, 1615) excertos dos textos dos jesuítas foram impressos antes da primeira edição de Araújo em 1618. Houve várias solicitações de impressão do catecismo por parte dos jesuítas no Brasil, mas não foram concretizadas. Pela importância que a impressão teria como forma de padronização do catecismo tupi, se solicitava, em 1592, a impressão do texto que já estava em uso há quarenta anos.

com se imprimir, será mais fácil tê-la todos, aprendê-la e ensinála, se pede a V. Paternidade dê para isso licença, porque pelo trabalho de a escrever muitos deixam de a ter, e os que a teem, não a teem certa; e cada um, se está um pouco adiantado na língua, lhe parece que se poderia dizer isto ou aquilo mehor, e assim a querem emendar a seu gôsto; com a ver impressa, entenderão que não há que emendar a seu gôsto. (carta de Beliarte, Bahia, 20 de setembro de 1592 apud Leite, 1938, v. 2, p. 558)

A impressão do primeiro catecismo tupi ocorreu em um momento em que a Companhia de Jesus disputava com os franciscanos a permissão para atuar na 
Amazônia. Esta conjuntura fez com que a impressão do catecismo fosse destinada à evangelização dos índios na Amazônia, como sugere o prólogo de Araújo:

Agora pera que os que escolhe pera obreiros da altíssima empresa da salvação dos poucos Índios, que escaparam, e se vão tendo aos mares das tribulaçoens (...), tenhao com que os possão perfeiçoar, \& reduzir os muitos, que o novo descobrimento do Maranhão lhes está oferecendo, ordenou por via do Reverendo padre Provincial Pedro de Toledo (...) se imprimir o catecismo, que nesta lingoa antigoamente composerao alguns Padres doctos, \& bons lingoas. (Araújo, 1952)

Desta forma, o catecismo de 1618, elaborado pelos jesuítas na costa do Brasil, foi dirigido à evangelização da Amazônia antes mesmo de os jesuítas terem permissão para trabalhar na região. A obra de Antônio de Araújo significou a oficialização de um discurso cristão em tupi para uso tanto nas missões na costa do Brasil como para a região do Grão-Pará e Maranhão, representando a sua padronização em relação à terminologia cristã em tupi.

O catecismo de Araújo foi a obra catequética de referência das missões na Amazônia, se observarmos a sua menção no "Regulamento das aldeias indígenas do Maranhão e Grão-Pará” (1658-1661 apud Beozzo, 1983, p. 188), documento que organizou a vida das missões jesuíticas até a expulsão dos jesuítas na segunda metade do século XVIII. A obra de Araújo é referida no Regulamento quando diz que nas segundas-feiras se deveria seguir a prática "do responsório na forma do Catecismo" (Beozzo, 1983, p. 197). Esta sessão faz parte do catecismo de 1618/1686 no capítulo em latim "Responsos, que nas Igrejas dos Índios custumão dizer os padres da Companhia, todas as segundas feiras do anno no fim da missa que dizem pelos defunctos de suas Igrejas" (Araújo, 1952, p. 152).

A passagem indica que o Regulamento e o catecismo de Araújo foram obras obrigatórias em todas as missões, além de terem os dois textos uma relação de complementaridade. A vigência do Regulamento jesuítico até a expulsão da Ordem indicaria a legitimidade do catecismo de Araújo até o século XVIII.

Outro sinal da presença do texto de Araújo como arquétipo para o catecismo em uso na Amazônia remete ao período em que Antônio Vieira chegou 
como visitador da Ordem na região. A obra de Araújo foi o modelo para a elaboração de um catecismo breve e um outro "brevíssimo" na Amazônia em 1653. Para manter a uniformidade do texto cristão em tupi na região, Vieira distribuiu essas versões breves para os jesuítas que estavam no Pará. As alterações na obra de Araújo ocorriam por ser ela muito extensa.

não sendo capazes de catecismo tão dilatado e miúdo como é o geral, que anda impresso, tomamos dele as cousas mais substanciais, e fizemos outro catecismo recopilado, em que, por muito breve e claro estilo, estão dispostos os mistérios necessários à salvação, e este é o que se ensina. (Vieira, 1970, p. 339-340)

No século XVIII, temos indícios da circulação da obra de Araújo nas missões da Amazônia, por meio de um dicionário português-tupi (França, 1859), que faz referência à segunda edição de Araújo quando exemplifica a forma de uso de algumas expressões no catecismo.

Mudar-se. Aieiyi, como do catecismo, pág. 72, regra $4^{\circ}$; vulgarmente aiegiy. (França, 1859, p. 91)

O texto remete a um diálogo sobre a Paixão de Cristo na obra de Araújo.

\section{Mudança na composição etnolingüística das missões religiosas do Baixo Amazonas no século XVIII e a formação da variedade tupi "corrupta"}

No mesmo ano da impressão da primeira edição do catecismo de Araújo (1618), os documentos jesuíticos realçam as semelhanças étnicas e lingüísticas 
entre os tupinambá da costa do Brasil e os da Amazônia, como conta em carta o jesuíta Pero Rodrigues:

Do Maranhão vão já os nossos por terra ao Pará que são 80 leguas de jornada, e os índios moradores daquella costa dão livre passagem, por serem Tupinambás, que são os mesmos que os desta Bahia. (Pero Rodrigues, 1618 apud Leite, 1938, v. 3, p. 426)

Um século depois, os documentos missionários descrevem uma outra situação etnolingüística nas missões do Baixo Amazonas: elas passaram a ter uma minoria tupinambá e um grande número de índios não tupi. É o que diz, em 1720, o jesuíta Domingos de Araújo ("as nações de línguas gerais são muy poucas"). O jesuíta João Daniel ratifica este quadro sociolingüístico sobre as missões no Baixo Amazonas: "Porém, como os primeiros, e verdadeiros topinambares já quase de todo se acabaram, e as missões se foram restabelecendo com outras mui diversas nações" (Daniel, 1976, v. 2, p. 225).

A mudança na composição étnica da região tinha surgido como resultado da política indigenista portuguesa de transformar as missões em reserva de mão-deobra indígena para os três setores coloniais (administradores, colonos e missionários). Sempre que a população das missões diminuía por mortes causadas por epidemias e maus tratos, os missionários eram autorizados a trazerem novos grupos. $\mathrm{O}$ repovoamento das missões ocorreu com índios de outras áreas da Amazônia, como o Rio Negro, que falavam línguas não-tupi. Esta política indigenista tornou a missão um espaço formado por índios de diferentes grupos étnicos e lingüísticos.

A "língua geral corrupta" teria surgido como resultado desta política de deslocamento de grupos indígenas de diferentes línguas para missões onde a vida era organizada em torno do tupi como língua franca.

João Daniel (1722-1776), na crônica "Tesouro Descoberto do Rio Amazonas", nos descreve as situações de uso das duas variedades tupi nas missões jesuíticas:

Nesta língua [tupinambá] se composeram ao princípio pelos primeiros missionários jesuítas o catecismo, e doutrina; e a 
reduziram a arte com regras, e termos fáceis de se aprender. Porém, como os primeiros, e verdadeiros topinambares já quase de todo se acabaram, e as missões se foram restabelecendo com outras mui diversas nações, e línguas, se foi corrompendo de tal sorte a língua geral topinambá, que já hoje são raros, os que a falam com a sua nativa pureza, e vigor; de sorte, que já os mesmos índios não percebem o catecismo, nem os que estudam a arte se entendem com os índios especialmente no Amazonas, como muitas vezes tem experimentado, e confessado os mesmos missionários, e índios, de sorte está viciada, e corrupta que parece outra língua diversa; mas a qual é a que se usa em todas as missões portuguesas do Amazonas, e a que aprendem as novas nações, que vão saindo dos matos, e as que estudam os missionários brancos, que tratam com índios não com regras, e preceitos da arte, mas pelo uso, e trato dos mesmos índios. (Daniel, 1976, v. 2, p. 225)

Daniel diferencia o repertório tupi nas missões entre uma variedade denominada "língua geral verdadeira" (ou " língua geral antiga"), identificada com as obras impressas, e "língua geral corrupta", usada nos contextos não religiosos. A variedade do tupi impresso estava ligada às situações religiosas, como as ocasiões de uso do catecismo e do aprendizado da língua pelo jesuíta recém-chegado na colônia: "artes [de Figueira e Anchieta] são, e tem sido ategora as que se usam em todas as missões" (Daniel, 1976, v. 1, p. 269). A variedade "corrupta", sem textos escritos, era usada nos demais domínios da vida das missões.

Em relação aos grupos sociais que usavam cada variedade, a "língua geral corrupta" era falada por um grupo heterogêneo lingüisticamente, que incluía os portugueses e os índios não-tupi, recentemente incorporados na vida das aldeias (os "índios novatos"). A "língua geral verdadeira" era falada pelos "tapijara", ou seja, os descendentes dos antigos índios das missões, mas que já mostravam dificuldade para entender a versão do catecismo.

porque se ainda os tapijaras (chamam-se tapijaras os índios descendentes dos primeiros fundadores das missões, e creados nelas) não intendem, nem percebem já os termos da verdadeira língua geral, nem a doutrina do catecismo, muito menos a perceberão os índios novatos; e não a percebendo tão bem não 
perceberão aos seus missionários que os ensinam pelo catecismo. (Daniel, 1976, v. 2, p. 227)

Também os dicionários manuscritos indicam que o léxico cristão empregado no catecismo já estava em desuso.

Algum dia. Amöára iran, id. para o tempo adiante, como está na Ave Maria; iran; porém não se usa. (França, 1859, p. 10)

Apesar de ser usada diariamente pelos missionários nas doutrinas, o desaparecimento desta variedade do tupi se deve a ter tido um uso restrito a fórmulas fixas (o catecismo), em oposição à variante da "língua geral corrupta", que não tinha roteiros pré-estabelecidos.

\section{Sinais da política de estandardização no corpus tupi setecentista}

Consulta às obras impressas sobre o tupi na elaboração dos manuscritos setecentistas

As gramáticas e os catecismos tupi impressos, elaborados por missionários "línguas" da costa do Brasil nos séculos XVI a XVIII, continuaram sendo consultados e tomados como referência de uso para os missionários na Amazônia no século XVIII, apesar de aquelas obras não refletirem mais a variedade do tupi em uso nas missões.

Um exemplo da manutenção do catecismo de Araújo como referência para os manuscritos setecentistas são as três versões da oração do Pai Nosso reproduzidas nesta época: Eckart (1778), Doutrina e perguntas dos mistérios (Ayrosa, 1950) e Gramática da língua geral do Brasil (Universidade de Coimbra). Elas seguem a versão impressa em Araújo (1618). 
Também as gramáticas impressas de Anchieta e de Figueira foram modelo para a elaboração das versões manuscritas. As duas gramáticas setecentistas do acervo da Biblioteca da Universidade de Coimbra escolheram o verbo "juca" (matar) para exemplificar a conjugação verbal, assim como fizera Anchieta (1990) e Figueira (1687). Para a gramática do guarani, Montoya havia optado por "amboé" (ensinar) para apresentar o paradigma verbal (Montoya, 1993, p. 81). A escolha por "juca" (matar) para o exemplo de conjugação verbal do tupi deve ter sido marcada pela ênfase que deu a literatura européia do século XVI aos tupinambás como canibais.

A obra de Eckart é a única que foge ao modelo de gramática usado por Anchieta e Figueira. Ele optou pelo gênero da "Janua Linguarum", baseado em Amaro de Reboredo (Rosa, 1994). Embora a obra Eckart não siga o modelo de gramática de Anchieta, este autor tem um papel importante ao longo da obra do missionário alemão, que, além de incluir informações sobre a vida do "taumaturgo", coteja formas lexicais e gramaticais dadas pelo jesuíta do século XVI com aquelas usadas nas missões da Amazônia. Eckart teve acesso à gramática de Anchieta por meio de um exemplar encontrado por ele na missão de Abacaxis, no rio Tapajós.

A difusão das obras impressas em tupi ocorreu pelas bibliotecas jesuíticas nos colégios e em algumas missões. Na lista dos livros da biblioteca do colégio jesuítico de Vigia, havia cinco exemplares do Catecismo da língua brasílica, de Araújo (a lista não menciona qual edição) (Leite, 1942). Apenas a Bíblia e o Concordantae Bibliorum tinham tantos exemplares.

Os dicionários setecentistas também citam com freqüência as obras impressas em tupi como referências para formas de uso. Um deles (França, 1859) cita a página em que determinada expressão se encontra nas obras impressas, $o$ que nos permite averiguar quais edições aquele missionário teve a sua disposição.

Examinar. Anheanhereco, como do catecismo, fol. 222; ou aïpyã mongheta: he propriamente examinar a consciência. (França, 1859, p. 63)

Levanto alguma couza commigo juntamento. Arapoam, segundo a arte, pág. 92. (França, 1859, p. 82) 
Pelos números das páginas é possível identificar a segunda edição de Araújo (1686) e a de Figueira (1687) como os exemplares disponíveis para o missionário.

\section{Estabelecimento da diglossia entre "língua geral verdadeira" versus "corrupta" através dos manuscritos setecentistas tupi}

A diglossia relatada por Daniel entre uma variedade tupi "antiga", identificada pelos textos jesuíticos impressos, e uma outra "corrupta", associada à variedade tupi oral usada fora dos contextos religiosos, está presente também nas gramáticas e dicionários manuscritos em tupi do século XVIII. Estes manuscritos não apenas ratificam o quadro sociolingüístico apresentado por Daniel, como foram além, ao estabelecerem limites e ao marcarem diferenças entre as variedades. Eles foram o principal instrumento de estabelecimento desta diglossia, ao diferenciarem o repertório lingüístico tupi do século XVIII entre estas duas variedades ("língua geral corrupta" versus "língua geral verdadeira"), processo que Câmara nomeou como disciplinarização.

Neste processo de diferenciação diglóssica, as gramáticas e os catecismos impressos em tupi são referidos nos verbetes dos dicionários como exemplos de uso.

Anno. Acajû e também çeixu; ia bió, cada anno, como no catecismo, nos Mandamentos da Santa Madre Igreja. (França, 1859, p. 15)

Amanhan. üírandê, L. öirandê; segundo a arte. curîuiêm. (França, 1859, p. 12)

Estes manuscritos atribuem valores distintos às duas variedades do tupi, opondo-as entre "polida" e "menos polida". 
BARROS, M. C. D. M. A relação entre manuscritos...

Najucai... Eu não mato...

Nitibi ajucá. Eu não mato.

Segunda frase menos polida, e mais uzada.

(Biblioteca da Universidade de Coimbra, 1758, p. 14)

Alguma vez. Amó ramé; vulgarmente e com mais elegancia se diz: amöme. (França, 1859, p. 10)

As formas "elegantes" eram aquelas encontradas nos textos dos jesuítas do século XVI, como se vê no exemplo acima de "alguma vez". A forma amome, que o dicionário setecentista considera como mais elegante, é a mesma que se usava no dicionário de 1621 de São Paulo:

Alguma vez, ou vezes. Amome. Amoamome. Amonime. Amoamonime. idem est Amunîgme. (Drumond, 1952, p. 31)

\section{Algumas posturas dos manuscritos em relação a regras do tupi corrupto: o caso da negação dos verbos}

Uma regra do repertório tupi do século XVIII identificada como sendo própria da variedade "corrupta" foi a negação do verbo por meio do acréscimo de nitio (ou niti, nitibi etc.) Esta forma de negar diferia daquela descrita nas gramáticas de Anchieta (1595) e de Figueira (1687). Este último assim explica a negação:

Pêra negarmos qualquer cousa nesta língua, se usa de vários modos de negações, todas anneixas ao verbo, compondose com ellas, e com o verbo affirmativo outro verbo negativo, com sua variedade de modos \& tempos, como iremos vendo. E todos, os verbos se negão da mesma maneira. E notese que as negações começão póla 
letra N, E também admittem a letra D, depois do N, ut Najucái, ou Ndajucái, ou com o D somente Dajucái. (Figueira, 1687, p. 24)

No século XVIII, os manuscritos mencionam as duas formas de negar, uma considerada mais elegante e a outra mais corrente. Uma gramática de 1758 preserva trechos da explicação da regra de negação da gramática de Figueira de 1678 , acrescentando ser esta a forma mais elegante, porém inclui a regra alternativa por meio de nitibi ou nitio:

Para negarmos qualquer couza nesta língua se uza de vários modos de negaçoens, todas annexas ao verbo, compondose com ellas, e com o verbo affirmativo outro verbo negativo: e note que todas as negações principião pela Letra $\mathrm{N}$, seja exemplo o verbo affirmativo Jucá, que significa matar: acrescentando nó hum N, a este verbo affirmativo, fica feito o verbo negativo na maneira seguinte: Ajucá, eu mato, Najucai, eu não mato: acrescentaseplhe também hum i, no fim par ficar mais elegante como se vê no verbo acima (...) Em lugar do dito N, se lhe pode ajuntar outra qualquer casta de negação,, como vg. Nitibi, Nitio, Nangai, Nangaité, Najucai, ou Najucá, Nitibi ajucá, Nitio ajucá, Nangai ajucá, Nangaité ajucá. (Biblioteca de Coimbra, 1758, p. 161-162)

Outro autor setecentista que inclui as duas regras de negar como uma oposição entre tupi “corrupto" e tupi "genuíno" (identificado com os tupinambá) é Anselmo Eckart (1778). Ele considera esta forma de negar por nitio como sendo própria das missões no Baixo Amazonas.

Deus non moritur, Tupà nomanói. este é genuíno modo de falar no Brasil o dialeto Toupinambeus (sic). Mas nas Missões Paraenses, onde o idioma já está um tanto quanto corrompido, assim dizem: Deus, Tupã, ou Tupána, non, nitiú, moritur, omanó. (Eckart apud Rosa, 1994, p. 177) 
Os dicionários setecentistas também incluíam as duas regras de negação, diferenciando-as pela oposição entre o vulgar (comum) e o elegante, como faz o dicionário do acervo da Academia de Ciências de Lisboa:

Abreviar, ou despajar. Naimomucúi. Vulgo. Niti amo inucú. L Nití amopucú. ut xe momucú ume iepé. Despachame. Naõ me detenhas. (Academia de Ciências de Lisboa)

O documento datado mais antigo que inclui o uso da negação com nitio é um dicionário português-tupi, de 1739, de frei João Arronches (Ayrosa, 1950), um franciscano que atuou em Gurupá (Catálogo, 2002).

\begin{tabular}{|l|l|}
\hline Nam presta & Nitiu catú \\
\hline Nam ouves & Nitiu recendú \\
\hline Nam tem remédio & Nitiu poçanga \\
\hline Nam há de suceder & Nitiu xoéri \\
\hline
\end{tabular}

Se as gramáticas e os dicionários do século XVIII diferenciam as duas regras de negação atribuindo diferentes valores para cada uma delas, qual dessas variedades - "elegante" ou "corrupta" - eram usadas nos catecismos oficiais? Tomaremos como exemplo o catecismo breve Compendio da Doutrina Cristan que se manda ensinar com preceito, ano de 1740 (Ayrosa, 1950), portanto um ano após o dicionário de frei Arronches, que já documentava o uso da negação verbal por meio do acréscimo de nitiu. O objetivo é saber que forma de negação este catecismo empregou nos diálogos de pergunta e resposta.

Antes de verificar a postura do catecismo de 1740 em relação à forma de negação, é necessária uma contextualização deste texto. Ele permite acompanhar o debate interno na Companhia de Jesus a respeito do catecismo e as ingerências da hierarquia jesuítica pela aprovação de um texto único para as missões na Amazônia, como forma de impedir a circulação de versões não autorizadas.

Segundo Leite, seu autor é o padre José Vidigal (1674-1748). O catecismo de 1740 surgiu a propósito de uma denúncia do Padre Salvador de Oliveira ao Padre Geral de que não havia padronização do catecismo tupi nas missões da Amazônia e que diferentes textos estavam sendo usados pelos missionários. 
Na carta de 1736, Oliveira sugere ao Padre Geral o nome de José Vidigal para se responsabilizar, com outros padres "línguas", pela revisão de um texto de catecismo breve que deveria ser usado uniformemente nas missões "definitivamente se guardasse e ensinasse em todas as missões, para todos sentirmos e dizermos a mesma coisa" (Salvador de Oliveira, 1736 apud Leite, 1944, p. 171). Em 1740, por uma carta do Padre Geral, sabemos que o catecismo breve de José Vidigal já estava concluído e que a palavra "preceito" havia sido incluída ao título, por ordem expressa do Padre Geral, para que os missionários não modificassem o texto.

Que opção o catecismo de 1740, aprovado pela hierarquia jesuítica, tem em relação à negação verbal? Sua escolha foi preservar a regra de negação presente nas obras impressas em tupi (acréscimo de $n$ - e outras modificações morfofonêmicas), e excluir a regra associada ao tupi corrupto (nitio), como se vê no exemplo abaixo tirado de um dos diálogos:

\begin{tabular}{|l|l|}
\hline Setépe Tupã asé oabé? & Tem Deus corpo como nós? \\
\hline Nasetei (Ayrosa, 1950, p. 73) & Não teve (Ayrosa, 1950, p. 87) \\
\hline
\end{tabular}

Postura diferente teve um catecismo, sem data e anônimo, que emprega a negação verbal pela regra da variedade do tupi "corrupto". Ao introduzir a variedade "corrupta" no catecismo, este autor define sua obra como uma "tradução" da obra de Bettendorff para "a língua g[eral] irregular, e vulgar uzada nestes tempos" (Doutrina cristaã em lingoa geral dos Índios, do acervo da Biblioteca da Universidade de Coimbra).

\section{Conclusão}

A tese de Câmara a respeito da ação prescritiva que os jesuítas tiveram sobre o tupi colonial foi o ponto de partida da análise de um conjunto de dicionários, gramáticas e catecismos manuscritos em tupi, originários da Amazônia no século XVIII. O objetivo foi estudar a política de estandardização do tupi no século XVIII considerando dois tipos de escrita, a impressa e a manuscrita. Neste período, o tupi das obras impressas não mais correspondia à variedade oral em uso nas missões. Procuramos conhecer que postura os 
missionários do século XVIII, ao escreverem as suas obras para uso particular, tiveram em relação às obras impressas na língua tupi.

Os manuscritos setecentistas deixam ver o missionário imerso em um dilema entre ser "elegante", ao seguir a norma tupi dos antigos textos, ou ser inteligível, ao empregar o tupi corrente no cotidiano das missões. Eles oscilam entre reproduzir regras e léxicos tupi não mais em uso, mas que constam dos textos impressos, e descrever a variedade tupi oral em uso nas missões, que não mais coincidiam com os textos impressos.

Porém, uma análise preliminar do corpus tupi setecentista indica que o grau de adesão dos missionários à política de estandardização do tupi pelas obras impressas variou em relação ao gênero do texto. Os catecismos foram os mais resistentes a absorver as regras e léxico do tupi corrupto, enquanto, em outro extremo, estariam os dicionários, que possuíam mais liberdade para incluir nos verbetes a variedade "corrupta". Como este gênero nunca foi impresso, ele não teve um padrão definido para ser seguido ao longo da evangelização. A diferente postura entre catecismo e dicionário pode ser vista em relação à regra de negar por nitio, traço do tupi "corrupto" presente no dicionário de Arronches de 1739 e ausente no catecismo oficial de 1740 (Ayrosa, 1950).

\section{RESUMO}

O trabalho analisa a política jesuítica de estandardização do tupi no período colonial a partir do estudo da relação entre impressos e manuscritos tupi. O artigo examina a posição de um conjunto de catecismos, gramáticas e dicionários manuscritos, produzidos na Amazônia no século XVIII, em relação à diglossia "língua geral verdadeira", identificada com a variante usada nas obras impressas nos séculos XVI e XVII (Anchieta, 1959; Figueira, 1621; 1698; Araújo, 1618; 1686) e a "língua geral corrupta", identificada pela variante tupi oral falada nas missões. O trabalho levanta a hipótese de que as obras apresentam diferentes posições segundo o tipo de gênero textual: os catecismos foram mais conservadores, ao se manterem fiéis à variante empregada nas obras tupi impressas, diferentemente dos dicionários e gramáticas, que documentaram a variante tupi em uso nas missões.

Palavras-chave: Língua geral, Amazônia, jesuitas, política lingüistica, historiografia lingüistica, século XVIII. 


\begin{abstract}
This paper analyses the Jesuits's policy of standardization of the Tupi language during Colonial times, and is based on the study of the nexus between manuscript and printed material in Tupi. It positions an ensemble of manuscript catechisms, grammars and dictionaries, composed in $18^{\text {th }}$ century's Amazon, between the "true Língua geral" diglossia - identified with the variant used in $17^{\text {th }}$ and $18^{\text {th }}$ centuries printed works (Anchieta, 1959; Figueira, 1621; 1698; Araújo, 1618; 1686) -, and the "corrupt Língua geral" - identified with the Tupi variation spoken in the Missions. We make the assumption that these compositions are differently settled in the scale regarding the textual genre: catechisms are more conservative, since they were faithful to the variety used in printed Tupi works, while dictionaries and grammars reflects the oral Tupi variant used in the Missions.

Key-words: Língua geral, Amazon, Jesuits, linguistic policy, linguistic historiography, $18^{\text {th }}$ century.
\end{abstract}

\title{
REFERÊNCIAS
}

ACADEMIA DE CIÊNCIAS DE LISBOA. Prosodia. Dicionario da Língua falada por índios do Brasil. Lisboa: Academia de Ciências de Lisboa.

ANCHIETA, José de. Artes de gramática da língua mais usada na costa do Brasil. São Paulo: Loyola, 1990.

ARAÚJO, Antônio de. Catecismo na língua brasilica. Rio de Janeiro: Olímpica, 1952. Fac-símile da edição de 1618.

. Catecismo Brasilico da doutrina christãa, com o cerimonial dos Sacramentos, \& mais actos Parochiaes. Composto Por Padres Doutos da Companhia de Jesus, Aperfeiçoado, E dado a luz pelo Padre Antônio de Araújo da Mesma Companhia. Emendado nesta segunda impressão Pelo Bertholameu de Leam da mesma Companhia. Lisboa: Na Officina Miguel Deslandes, 1686.

ARAÚJO, Domingos de. Chronica da Companha de Jesus na Missão do Maranhão. Arq. 1.2.32. Rio de Janeiro: Instituto Histórico e Geográfico Brasileiro, 1720.

AYROSA, Plínio. O caderno da lingua ou vocabulário portuguez-tupi de Frei João de Arronches. 1739. Notas e commentarios à margem de um manuscripto do século XVIII. Revista do Museu Paulista, t. 21, 1937. 
BARROS, M. C. D. M. A relação entre manuscritos...

. Vocabulário na língua brasílica. Manuscrito português-tupi do século XVII, coordenado e prefaciado por Plínio Ayrosa. São Paulo: Departamento de Cultura, 1938.

. Orações e diálogos da doutrina cristã na língua brasílica. Mss. do século XVIII. Boletim de Etnografia e Lingua Tupi-guarani, São Paulo, n. 17, 1950.

. Vocabulário português-brasílico. Mss. do século XVIII transcritos e ordenados. Boletim de Etnografia e tupi-guarani, São Paulo, n. 21, 1951.

BEOZZO, José Oscar. Leis e regimentos das missões. Política indigenista no Brasil. São Paulo: Loyola, 1983.

BETTENDORFF, João Felipe. Compêndio da Doutrina Christam na Língua Portuguesa, e Brasilica. Lisboa: Imprensa Miguel Deslandes, 1687.

BIBLIOTECA DA UNIVERSIDADE DE COIMBRA. Gramatica da Lingua Geral do Brazil. Com hum diccionario dos vocabulos mais uzuaes para a intelligencia da dita lingua. Pará: Biblioteca da Universidade de Coimbra, [1758?]. Ms. 69.

BLUTEAU, R. Vocabulário Português e Latino. Rio de Janeiro: Universidade Estadual do Rio de Janeiro. 1 CD-ROM.

BOXER, Charles Ralph.1956. A tentative check-list of Indo-Portuguese imprints, 15561674. Goa: [s.n.], 23 p., 7 f.: il.; 25 cm. Separata Boletim do Instituto Vasco da Gama, n. $73,1956$.

CÂMARA JUNIOR, Joaquim Mattoso. Dicionário de Filologia e gramática referente à língua portuguesa. Rio de Janeiro. J. Ozon, 1964. 1965.

. Introdução às línguas indígenas brasileiras. Rio de Janeiro: Museu Nacional,

CARDOSO, Pe. Armando. Introdução histórico-literária, tradução e notas. In: ANCHIETA, José de. Doutrina cristã. São Paulo: Loyola, 1992. t. 2: Doutrina autógrafa e confessionário. (Obras Completas, 10).

CATÁLOGO de documentos manuscritos avulsos da capitania do Pará existentes no arquivo histórico ultramarino de Lisboa. Belém: Secult/Apep, 2002. Projeto Resgate. 3 v.

DANIEL, João. Tesouro descoberto no Rio Amazonas. Rio de Janeiro: Biblioteca Nacional, 1976. $2 \mathrm{v}$.

DRUMOND, Carlos. Vocabulário na Língua brasílica. 2. ed. rev. e confrontada com o ms. fg. 3144 da Biblioteca Nacional de Lisboa. Boletim de Etnografia e tupi-guarani, São Paulo, n. 23, 1952. 
ECKART, Anselm. O Exemplário da língua corrente do Brasil de Anselm von Eckart. Trad. por: Carlos Antônio Kalil Tannus e Miguel Barbosa Rosário. Terceira margem. Revista da Pós-graduação em Letras da UFRJ, Rio de Janeiro, ano 2, n. 2, p. 176-180, 1994.

. Specimen Liguae Brasilicae vulgaris. In: MURR, Christoph Gottlieb von. Nuernberg. Journal zur Kunstgeschichte und zur Allgemeinen Litteratur, v. 17, n. 2, 1778.

D'EVREUX, Ýves. Voyage dans le Nord du Brésil. Publié d'apres l'exemplaire unique conservé a la Bibliotheque Impériale de Paris. Avec une introduction et des notes par M. Ferdinand Denis. Leipzig \& Paris: Librairie A. Franck, 1864.

FASOLD, Ralph. The sociolinguistics of society. Oxford: Blackwell, 1996.

FERNANDES-VIEIRA, Manuel. A “Doutrina christam” do P. Marcos Jorge. Pamplona, 1981. Tese (Doutorado) - Facultad de Teologia, Universidad de Navarra.

FIGUEIRA, Luis. Arte de grammatica da lingua brasílica. Lisboa: Officina de Miguel Deslandes, 1687.

. Arte da lingua Brasilica, composto pelo padre Luis Figueira da Companhia de Jesus, theologo. Lisboa: Manoel da Silva, 1621.

FRANÇA, Ernesto Ferreira. Chrestomathia da língua brazilica. Leipzig: F. A. Brockhaus, 1859.

HISTORIA de la fundación del Collegio de la Baya de todo los Sanctos, y de sus residencias. Anais da Biblioteca Nacional, Rio de Janeiro, n. 19, p. 77-121, 1897. Biblioteca Nacional do Rio de Janeiro.

JORGE, Marcos; MARTINS, Ignacio. Doctrina Christã. Ordenada a maneira de Dialogos, pera ensinar os mininos, pelo Padre Marcos Jorge da Companhia de IESU, Doctor em Theologia. Acrescentada pelo Padre Ignacio Maz, da mesma Companhia, Doctor Theologo. Lisboa: Impresso com licença por Pedro Crasbeeck, 1602.

LEITE, Serafim. História da Companhia de Jesus no Brasil. Rio de Janeiro: Instituto Nacional do Livro, 1938-1950. 10 v.

. Uma biblioteca portuguesa no Brasil dos tempos coloniais. Casa de Vigia, Pará. Brasilia, Coimbra, v. 1, p. 257-267, 1942.

. José Vidigal, autor do "Compêndio da Doutrina cristã na língua brasileira”.Verbum, Rio de Janeiro, v. 1, p. 170-172, 1944. 
BARROS, M. C. D. M. A relação entre manuscritos...

. Monumenta Brasiliae. [S.1.], 1956-1960. (Monumenta Historica, v. 79-81;87).

LEITE, Yone. A gramática de Anchieta: 500 anos de língua tupi. Ciências Hoje, Rio de Janeiro, v. 28, n.168, p. 42-47, 2000.

MARUYAMA, Toru. A comparative study of the interrogatives appearing in Portuguese, Kikongo, Konkani and Japanese versions of Christian Doctrine in the sixteenth and seventeenth centuries. Academia: Literature and Language, n. 65, 1998.

. Selective bibliography concerning the jesuit mission press in the sixteenth and seventeenth centuries. Nanzan University, 1996.

MONTOYA, Antonio Ruiz. Arte de la Lengua Guarani. Asunción: Cepag, 1993.

MORAES, José. História da Companhia de Jesus da Província do Maranhão e Pará. Conselho Ultramarino, Évora. Cópia do IHGB. 1759.

MONSERRAT, Ruth Maria. O tupi do século XVIII. In: COLÓQUIO DA LÍNGUA GERAL, 2., 2000, Rio de Janeiro.

ORE, Luis Jeronimo. Rituale seu Manuale Peruanum. Nápoles, 1607.

RODRIGUES, Aryon D. Descripción del tupinambá en el período colonial: el Arte de José de Anchieta. In: ZIMMERMANN, Klaus (Ed.). La descripción de las lenguas ameríndias en la época colonial. Biblioteca Ibero-Americana. Frankfurt: Vervuert, 1997. p. 371-400.

ROSA, Maria Carlota. Um exemplo de descrição pedagógica no século XVIII: o Specimen linguae brasilicae vulgaris e a tradição jesuítica de ensino de segunda língua. Terceira Margem. Revista da Pós-graduação em Letras da UFRJ, Rio de Janeiro, ano 2, n. 2, p. 181-189, 1994.

THEVET, Andre. La Cosmographie Vniverselle d'Andre Thevet cosmographe dv Roy. Illustree de Diverses figures des chosesplus remarquables vevë par l'Auteur, \& incogneuës de noz Anciens \& Modernes. A Paris Chez Pierre 1'Huillier, rue S. Jacques, à l'Olivier. 1575. Avec Privilege du Roy. t. 2.

VIEIRA, Antônio. Cartas do Padre Antônio Vieira: coordenadas e anotadas por J. Lúcio de Azevedo. Lisboa: Imprensa Nacional, 1970-1971. 3 v. 
ANEXO - MANUSCRITOS TUPI DE MISSÕES NA AMAZÔNIA NO SÉCULO XVIII

\begin{tabular}{|c|c|c|c|c|c|c|c|}
\hline & 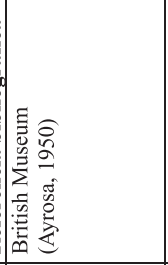 & 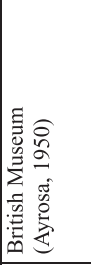 & 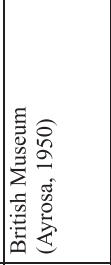 & 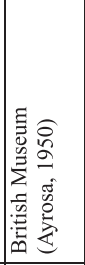 & 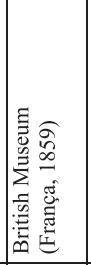 & 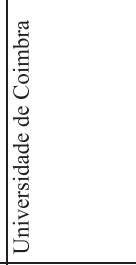 & 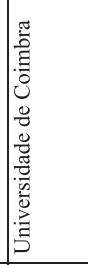 \\
\hline 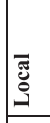 & & & & & & & 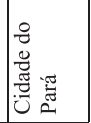 \\
\hline$\stackrel{8}{\ell}$ & 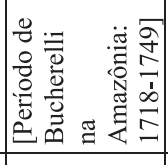 & $\begin{aligned} \frac{5}{1} \\
0 \\
0\end{aligned}$ & 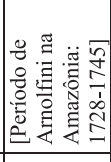 & & & & $\underline{E}$ \\
\hline $\begin{array}{l}\stackrel{a}{\frac{g}{2}} \\
\frac{1}{4}\end{array}$ & 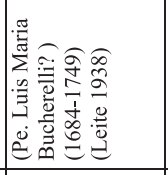 & 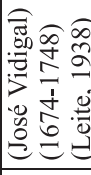 & 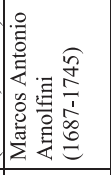 & & & & \\
\hline 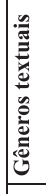 & 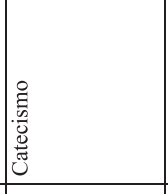 & 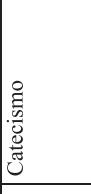 & 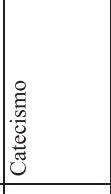 & 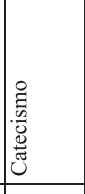 & 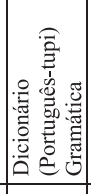 & 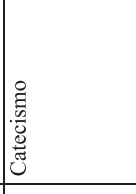 & 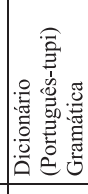 \\
\hline 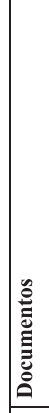 & 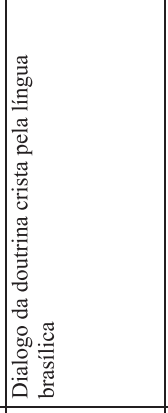 & 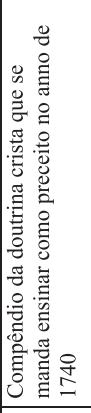 & 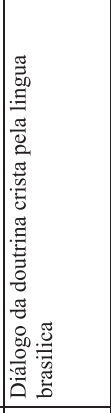 & 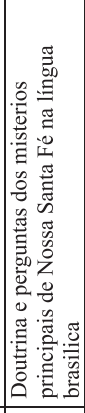 & 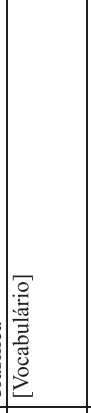 & 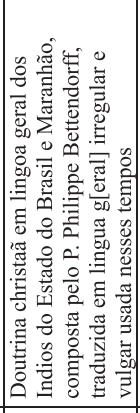 & 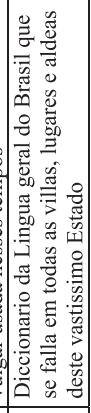 \\
\hline & - & i & $m$ & $\dot{\nabla}$ & in & 0 & ri \\
\hline
\end{tabular}


BARROS, M. C. D. M. A relação entre manuscritos...

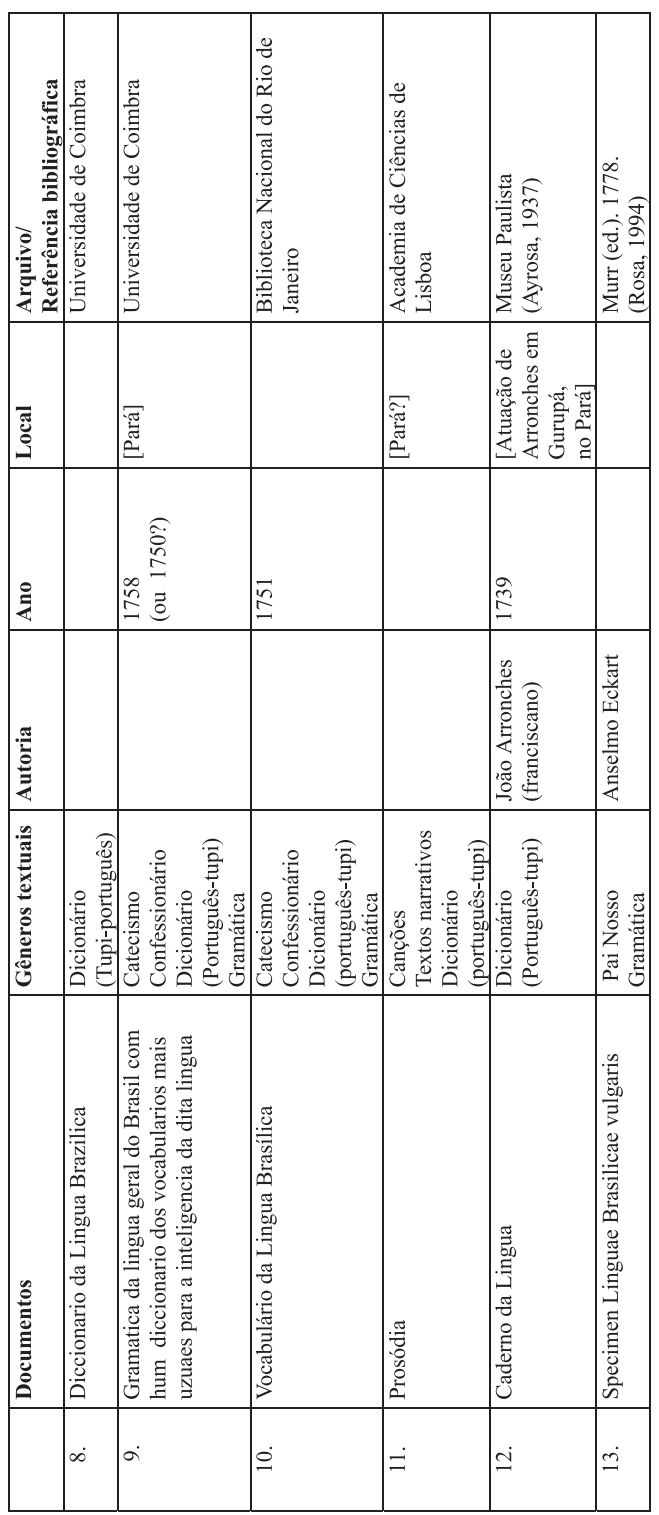

